\section{RSP}

http://www.rsp.fsp.usp.br/
Revista de Saúde Pública

\title{
Polypharmacy: a challenge for the primary health care of the Brazilian Unified Health System
}

\author{
Renata Cristina Rezende Macedo do Nascimento', Juliana Álvares", Augusto Afonso Guerra \\ Junior", Isabel Cristina Gomes"II, Micheline Rosa Silveira", Ediná Alves Costa ${ }^{\mathrm{IV}}$, Silvana Nair Leitev, \\ Karen Sarmento Costa ${ }^{\mathrm{VI}, \mathrm{VII}, \mathrm{VIII}}$, Orlando Mario Soeiro ${ }^{\mathrm{IX}}$, Ione Aquemi Guibu ${ }^{\mathrm{X}}$, Margô Gomes de \\ Oliveira Karnikowski ${ }^{\mathrm{XI}}$, Francisco de Assis Acurcio" \\ Programa de Pós-Graduação em Medicamentos e Assistência Farmacêutica. Faculdade de Farmácia \\ Universidade Federal de Minas Gerais. Belo Horizonte, MG, Brasil \\ " Departamento de Farmácia Social. Faculdade de Farmácia. Universidade Federal de Minas Gerais. \\ Belo Horizonte, MG, Brasil \\ III Faculdade de Ciências Médicas. Belo Horizonte, MG, Brasil \\ Iv Instituto de Saúde Coletiva. Universidade Federal da Bahia. Salvador, BA, Brasil \\ $\checkmark$ Departamento de Ciências Farmacêuticas. Universidade Federal de Santa Catarina. Florianópolis, SC, Brasil \\ vı Núcleo de Estudos de Políticas Públicas. Universidade Estadual de Campinas. Campinas, SP, Brasil \\ vII Programa de Pós-Graduação em Saúde Coletiva. Departamento de Saúde Coletiva. Faculdade de Ciências \\ Médicas. Universidade Estadual de Campinas. Campinas, SP, Brasil \\ VIII Programa de Pós-Graduação em Epidemiologia. Faculdade de Medicina. Universidade Federal do Rio Grande do Sul. \\ Porto Alegre, RS, Brasil \\ Ix Faculdade de Ciências Farmacêuticas. Pontifícia Universidade Católica de Campinas. Campinas, SP, Brasil \\ x Departamento de Saúde Coletiva. Faculdade de Ciências Médicas. Santa Casa de São Paulo. São Paulo, SP, Brasil \\ xı Faculdade de Ceilândia. Universidade de Brasília. Brasília, DF, Brasil
}

\begin{abstract}
Correspondence:
Renata Cristina Rezende Macedo do Nascimento

Universidade Federal de Minas Gerais Av. Presidente Antônio Carlos, 6627 31.270-901 Belo Horizonte, MG, Brasil E-mail: recmacedo@gmail.com
\end{abstract}

Received: Mar 30, 2016

Approved: Feb 07, 2017

How to cite: Nascimento RCRM, Álvares J, Guerra Junior AA, Gomes IC, Silveira MR, Costa EA, et al. Polypharmacy: a reality in the primary health care of the Brazilian Unified Health System. Rev Saude Publica. 2017;51 Suppl 2:19s.

Copyright: This is an open-access article distributed under the terms of the Creative Commons Attribution License, which permits unrestricted use, distribution, and reproduction in any medium, provided that the original author and source are credited.

\section{ABSTRACT}

OBJECTIVE: To characterize the polypharmacy in primary health care patients and to identify its associated factors.

METHODS: This is a cross-sectional, exploratory, and evaluative study, part of the Pesquisa Nacional sobre Acesso, Utilização e Promoção do Uso Racional de Medicamentos - Serviços, 2015 (PNAUM - National Survey on Access, Use and Promotion of Rational Use of Medicines - Services, 2015). The variable of interest was polypharmacy, defined as the use of five or more medicines. We sought to identify the association of sociodemographic variables and indicators of health conditions to polypharmacy. For group comparison, the Pearson's Chi-square test was used. The association between polypharmacy and explanatory variables was evaluated by logistic regression model $(\mathrm{p}<0.05)$. The quality of the adjustment was verified by Hosmer-Lemeshow test.

RESULTS: The prevalence of polypharmacy among medicine users was $9.4 \%$ (95\%CI 7.8-12.0) in the general population and $18.1 \%$ (95\%CI 13.6-22.8) in older adults above 65 years old. We found statistically significant association between polypharmacy and age above 45 years, lower self-perception of health, presence of chronic diseases, having health insurance, care in emergency services, and region of the Country. South users presented the highest chances to polypharmacy. The most used medicines were those of the cardiovascular system, being compatible with the national epidemiological profile.

CONCLUSIONS: Polypharmacy is a reality in the population met within the primary care of Brazilian Unified Health System and may be related to excessive or inappropriate use of medicines. The main challenge to qualify health care is to ensure that prescription of multiple medicines be appropriate and safe.

DESCRIPTORS: Polypharmacy. Risk Factors. Patient Safety. Pharmaceutical Services. Primary Health Care. Health Services Research. Unified Health System. 


\section{INTRODUCTION}

The provision of health care is quite complex and requires the necessary balance between benefits and risks that accompany the whole process, to provide people the most complete well-being ${ }^{10}$. Patient safety, understood as reduction of the risk of unnecessary damage associated with care, has been considered a priority attribute of the health systems quality throughout the world ${ }^{10,17}$. In the context of primary health care, inappropriate correlation between diagnosis and prescribed treatment and misuse of medicines and problems of communication between physicians and patients are the main causes of adverse events ${ }^{19}$.

The use of multiple medications, or polypharmacy, is increasingly common in clinical practice, particularly in people over 65 years old. This growth is related to multiple factors, such as increased life expectancy and the consequent growth in the prevalence of multimorbidity, the enhanced availability of drug treatments and guidelines that recommend the use of more than one drug in the management of several health conditions, such as hypertension and diabetes mellitus ${ }^{7,15}$. The optimized association of medicines, prescribed according to the best available evidence, can heal, minimize damage, increase longevity, and improve quality of life ${ }^{6}$. However, some therapies are inadequate and may cause adverse reactions and drug interactions ${ }^{16}$.

One of the challenges in discussing polypharmacy and the associated medication safety is the absence of a universally accepted polypharmacy definition ${ }^{7,21}$. Most of the concepts identified by Bushardt et al. ${ }^{6}$ relate the term to exacerbated and inappropriate use of medicines. The reasons that explain this practice are treatments not based on evidence; the adoption of combinations with potential drug interactions; the pharmacological treatment of the side effects of other medicines; and the simultaneous prescription by multiple doctors, without the necessary therapeutic conciliation for the patient.

The inappropriate drug therapy is a serious problem for health systems, being recognized as a costly practice ${ }^{6}$. According to the World Health Organization ${ }^{28}$, about $50 \%$ of patients with chronic diseases do not adhere to pharmacological treatments, $4 \%$ to $5 \%$ of the hospital admissions occur because of preventable adverse events, and about $30 \%$ of emergency consultations are generated by medicine-related problems, many of them preventable.

Adverse drug events (ADE) are a common and costly complication in health care, representing the fifth cause of death in the United States 5 . The age of the patient and polypharmacy are factors associated with the higher number of doctor's appointments and the occurrence of $\mathrm{ADE}^{5}$. Avoiding the use of unsuitable and high-risk medicines is an important and effective strategy to reduce the problems related to drug treatment, especially in older adults. However, there are important gaps in the knowledge about this phenomenon, and the best evidence come from hospital environments ${ }^{28}$.

Few studies have assessed polypharmacy in the context of primary health care and in public health systems ${ }^{28}$. Also, the scientific evidence of drug effectiveness come from randomized clinical trials, excluding elderly, people with comorbidities, and polypharmacy ${ }^{13}$. Thus, most of the articles published in the literature do not provide information directly relevant to the people who need drug associations. Studies on these events in the real world are especially important for a better understanding of the challenges in providing quality health care ${ }^{25}$.

The Pesquisa Nacional sobre Acesso, Utilização e Promoção do Uso Racional de MedicamentosServiços, 2015 (PNAUM - National Survey on Access, Use and Promotion of Rational Use of Medicines - Services, 2015) aimed to characterize the organization of pharmaceutical services in primary health care of the Brazilian Unified Health System (SUS), to promote access and rational use of medicines, as well as identify and discuss factors that interfere in the consolidation of pharmaceutical services in municipalities. In this context, this study, part of PNAUM - Services, aims to characterize the polypharmacy in patients of the SUS primary health care and to identify its associated factors, to provide subsidies for the improvement of health care in Brazil. 


\section{METHODS}

This article is part of PNAUM, a cross-sectional, exploratory, and evaluative study, consisting of an information gathering in a representative sample of cities, primary health care services, patients, physicians, and drug dispensers in the five regions of Brazil. The sampling plan considered the various study populations and estimated the sample sizes for each of these populations ${ }^{1}$. For each region, 120 cities, 300 health services, and 1,800 patients were sampled. The total sample of patients $(9,000)$ was estimated considering the possibility of up to $20 \%$ loss. Patients were interviewed in primary health care services, with a specific structured questionnaire. After the training of the interviewers, a pretest was carried out, involving cities with different population sizes to detect opportunities for improving and to validate the questionnaires. The data were collected from July 2014 to May 2015.

Respondents were asked about the knowledge of chronic diseases diagnosed by a health professional; about emergency care and hospitalization in the 12 months preceding the interview; and about physical activity ( frequency in the three previous months), smoking (frequency and quantity of cigarettes), and alcohol use (occurrence, frequency, and number of doses). Regarding the use of medicines, all medicines used in 30 days prior to the interview were registered, according to self-report. To ensure greater accuracy, patients were requested to hand in the prescriptions and/or packages of medicines in use, when available. The subjects were divided into three strata, according to the number of medicines used: one, two to four, and five or more medicines. The variable of interest was polypharmacy, defined as the use of five or more medicines. The medicines were classified according to the fifth level of the Anatomical Therapeutic Chemical index (ATC) ${ }^{29}$ and described using the Denominação Comum Brasileira (DCB - Brazilian Common Name). The Beers criteria was used to identify the use of potentially inappropriate medications for older adults in the population of the study ${ }^{3}$.

The association between polypharmacy and sociodemographic variables (gender, age, marital status, educational level, economic class, and having health insurance), lifestyle (alcohol consumption, smoking, physical activity practice), and indicators of health conditions (self-perception of health, number and main chronic diseases self-reported, emergency care and hospitalization) was assessed. These variables were included in the study by their epidemiologic importance and for being associated with polypharmacy in several pharmacoepidemiologic studies ${ }^{4,8,14,21}$.

Absolute and relative frequencies were used to describe the variables, using the program $\mathrm{R}^{\circ}$ version 3.2.1, with the survey package ${ }^{\mathrm{a}}$. For group comparison, the Pearson's Chi-square test with Rao-Scott correction was adopted, considering a significance level of $5 \%$. The association between polypharmacy and explanatory variables was evaluated by logistic regression model. Univariate models were used to select variables to the multiple model, being eligible those with $\mathrm{p}$-value lower than or equal to 0.20 . The selected variables in the univariate models were included in the multiple model. The backward method was adopted to obtain the final model, where the variables with p-value lower than 0.05 remained. The adjustment quality was verified by Hosmer-Lemeshow test.

The research was approved by the National Research Ethics Committee (CONEP), under Opinion no. 398,131/2013. All the interviews were preceded by the clarification of the research's goals to the respondent and by the signature of the informed consent form.

aT. Lumley "survey: analysis of complex survey samples". $\mathrm{R}$ package version 3.30. Vienna: The R Foundation; 2014.

\section{RESULTS}

Interviews were carried out with 8,803 patients in primary health care services of 272 Brazilian cities, $97.8 \%$ of the planned sample. Of these, 6,511 used at least one medicine. Polypharmacy (use of five drugs or more) was identified in 9.4\% (95\%CI 7.8-12.0) of medicine users. The 
majority of polypharmacy patients were female (79.9\%, 95\%CI 75.2-83.9), aged between 45 and 64 years $(54.8 \%, 95 \% \mathrm{CI} 49-60.5)$, married or in common-law marriage $(64.6 \%$, 95\%CI 58.5-70.3), with some elementary school (54.7\%, 95\%CI 47.1-62.1\%), economic class C (54.0\%, 95\%CI 48.7-59.3), lived in the South region (49.5\% CI95\% 34.4-61.0), and without health insurance (83.0\%, 95\% CI 75.5-88.5). Among those who were on polypharmacy, 32.9\% (95\%CI 28.2-38.0) were older adults above 65 years old (Table 1). The prevalence of polypharmacy in this group was $18.1 \%$ (95\%CI 13.6-22.8\%).

Regarding the self-reported lifestyle and health characteristics, 5.9\% (95\%CI 3.8-9.1) of patients on polypharmacy consumed alcohol more than once per month, $14.7 \%$ (95\%CI 10.6-20.1) were smokers, and $29.6 \%$ (95\%CI 24.7-35.0) practiced physical exercise or sports in the three months preceding the interview (Table 2). Most polypharmacy patients

Table 1. Socioeconomic characteristics of medicine users in the SUS primary health care. Nacional Survey on Access, Use and Promotion of Rational Use of Medicines - Services, 2015.

\begin{tabular}{|c|c|c|c|c|c|c|c|}
\hline \multirow{3}{*}{ Variable } & \multicolumn{6}{|c|}{ Number of medicines } & \multirow{3}{*}{ p } \\
\hline & \multicolumn{2}{|c|}{$\begin{array}{c}1 \\
(n=2,561)\end{array}$} & \multicolumn{2}{|r|}{$\begin{array}{c}2-4 \\
(n=3,340)\end{array}$} & \multicolumn{2}{|r|}{$\begin{array}{l}5 \text { or more } \\
(n=610)\end{array}$} & \\
\hline & $\mathbf{n}^{*}$ & $\%(95 \% \mathrm{Cl})$ & $\mathrm{n}^{*}$ & $\%(95 \% \mathrm{Cl})$ & $\mathrm{n}^{*}$ & $\%(95 \% \mathrm{Cl})$ & \\
\hline Gender & & & & & & & 0.146 \\
\hline Female & 1,922 & $74.7(71.8-77.5)$ & 2,610 & $76.7(74.2-79.0)$ & 492 & $79.9(75.2-83.9)$ & \\
\hline Male & 639 & $25.3(22.5-28.2)$ & 730 & $23.3(21.0-25.8)$ & 118 & $20.1(16.1-24.8)$ & \\
\hline Age (years) & & & & & & & $<0.001$ \\
\hline $18-44$ & 1,541 & $58.8(55.9-61.7)$ & 1.266 & $35.7(32.2-39.2)$ & 64 & $12.3(8.8-17.0)$ & \\
\hline $45-64$ & 746 & $30.7(28.2-33.3)$ & 1.414 & $43.5(41.3-45.8)$ & 339 & $54.8(49.0-60.5)$ & \\
\hline$\geq 65$ & 240 & $10.4(8.6-12.6)$ & 640 & $20.8(18.1-23.9)$ & 207 & $32.9(28.2-38.0)$ & \\
\hline Marital status & & & & & & & $<0.001$ \\
\hline Married/commom-law marriage & 1,608 & $64.2(61.5-66.9)$ & 2.058 & $66.4(64.1-68.7)$ & 350 & $64.6(58.5-70.3)$ & \\
\hline Single & 686 & $24.5(22.0-27.2)$ & 718 & $17.2(15.5-19.0)$ & 70 & $9.1(6.7-12.2)$ & \\
\hline Others & 267 & $11.3(9.6-13.2)$ & 564 & $16.3(14.5-18.3)$ & 190 & $26,3(21.2-32.1)$ & \\
\hline Educational level & & & & & & & $<0.001$ \\
\hline Illiterate & 187 & $8.4(6.7-10.5)$ & 349 & $11.9(9.1-15.5)$ & 112 & $18.5(13.4-24.9)$ & \\
\hline Some elementary or middle school & 857 & $37,9(34,6-41,3)$ & 1,344 & $44.7(40.2-49.2)$ & 309 & $54.7(47.1-62.1)$ & \\
\hline Elementary or middle school & 348 & $13.7(10.9-17.2)$ & 416 & $12.1(9.9-14.6)$ & 71 & $10.9(7.6-15.3)$ & \\
\hline High school & 964 & $33.0(30.1-36.0)$ & 993 & $25.5(22.4-28.9)$ & 96 & $13.3(9.8-17.8)$ & \\
\hline Higher education & 205 & $6.9(5.5-8.7)$ & 238 & $5.8(4.7-7.2)$ & 22 & $2.6(1.5-4.4)$ & \\
\hline Economic class & & & & & & & 0.844 \\
\hline$A$ or $B$ & 443 & $16.0(13.2-19.2)$ & 532 & $14.7(12.2-17.7)$ & 97 & $14.1(9.8-19.7)$ & \\
\hline $\mathrm{C}$ & 1,488 & $54.6(50.7-58.4)$ & 1,954 & $54.5(50.6-58.4)$ & 348 & $54.0(48.7-59.3)$ & \\
\hline $\mathrm{D}$ or $\mathrm{F}$ & 627 & $29.5(24.7-34.7)$ & 853 & $30.7(25.6-36.4)$ & 165 & $31.9(25.0-39.7)$ & \\
\hline Country region & & & & & & & $<0.001$ \\
\hline North & 491 & $6.2(4.7-8.2)$ & 522 & $4.7(3.5-6.3)$ & 26 & $1.2(0.7-2.3)$ & \\
\hline Northeast & 483 & $29.4(21.5-38.6)$ & 621 & $29.9(21.5-39.8)$ & 75 & $22.1(13.8-33.5)$ & \\
\hline Midwest & 507 & $7.1(5.3-9.6)$ & 461 & $4.4(2.9-6.7)$ & 77 & $3.5(1.6-7.5)$ & \\
\hline Southeast & 571 & $36.6(28.3-45.7)$ & 694 & $32.6(23.4-43.3)$ & 119 & $27.2(18.1-38.9)$ & \\
\hline South & 494 & $20.7(16.2-26.1)$ & 891 & $28.4(20.2-38.4)$ & 275 & $45.9(34.4-61.0)$ & \\
\hline Has health insurance (yes) & 215 & $9.0(6.6-12.1)$ & 300 & $9.5(6.7-13.3)$ & 89 & $17.0(11.5-24.5)$ & 0.001 \\
\hline
\end{tabular}

* non-weighted n-value.

Source: PNAUM- Services, 2015. 
classified their health as neither bad/nor good (51.1\%, 95\%CI 45.3-56.9) and reported having two or more chronic conditions (95.1\%, 95\%CI 92.1-97.0). The main reported diseases were hypertension (84.3\%, 95\%CI 79.9-87.9), dyslipidemia (57.8\%, 95\%CI 51.863.6), arthritis, arthrosis, or rheumatism (51.3\%, 95\%CI 44.8-57.7), and depression (47.3\%, 95\%CI 40.9-53.9), and diabetes mellitus (41.6\%, 95\%CI 36.6-46.8). Among the 25 most used medicines by polypharmacy patients, 13 (52.0\%) belong to group C of the ATC, having action on the cardiovascular system. The most used drugs were simvastatin, losartan, and omeprazole (Table 3). Among the most used medicines, we highlight amitriptyline, clonazepam, diazepam, fluoxetine, and ibuprofen, belonging to the list of potentially inappropriate items for use in older adults, according to Beers criteria ${ }^{3}$.

The results of univariate and multiple logistic models for the polypharmacy predictors are presented in Table 4. Individuals with health insurance were 1.6 times more likely to be in

Table 2. Lifestyle characteristics and health condition indicators of patients attended by SUS primary health care. National Survey on Access, Use and Promotion of Rational Use of Medicines - Services, 2015.

\begin{tabular}{|c|c|c|c|c|c|c|c|}
\hline \multirow{3}{*}{ Variable } & \multicolumn{6}{|c|}{ Number of Medicines } & \multirow{3}{*}{$\mathbf{p}$} \\
\hline & \multicolumn{2}{|r|}{$\begin{array}{c}1 \\
(n=2,561)\end{array}$} & \multicolumn{2}{|r|}{$\begin{array}{c}2-4 \\
(n=3,340)\end{array}$} & \multicolumn{2}{|r|}{$\begin{array}{c}5 \text { or more } \\
(\mathrm{n}=610)\end{array}$} & \\
\hline & $\mathbf{n}^{\mathrm{a}}$ & $\%(95 \% \mathrm{Cl})$ & $n^{a}$ & $\%(95 \% \mathrm{Cl})$ & $\mathbf{n}^{\mathrm{a}}$ & $\%(95 \% \mathrm{Cl})$ & \\
\hline Alcohol use $(y e s)^{b}$ & 339 & $12.9(11.0-15.1)$ & 343 & $9.4(7.9-11.1)$ & 40 & $5.9(3.8-9.1)$ & $<0.001$ \\
\hline Smoking (yes) & 319 & $13.2(11.6-15.0)$ & 405 & $13.4(11.5-15.5)$ & 87 & $14.7(10.6-20.1)$ & 0.783 \\
\hline Practice of physical activity (yes) ${ }^{c}$ & 662 & $23.6(20.5-27.0)$ & 924 & $27.9(24.0-32.2)$ & 184 & $29.6(24.7-35.0)$ & 0.007 \\
\hline Self-perception of health & & & & & & & $<0.001$ \\
\hline Very good/good & 1,645 & $63.0(59.2-66.5)$ & 1,613 & $48.5(44.8-52.2)$ & 173 & $25.7(21.8-30.2)$ & \\
\hline Neither bad/nor good & 777 & $31.7(29.2-34.3)$ & 1,388 & $41.9(39.0-44.9)$ & 307 & $51.1(45.3-56.9)$ & \\
\hline Bad/very bad & 135 & $5.4(3.8-7.5)$ & 334 & $9.6(8.1-11.3)$ & 129 & $23.2(18.5-28.6)$ & \\
\hline Number of chronic diseases & & & & & & & $<0.001$ \\
\hline None & 1,036 & $39.0(36.0-42.2)$ & 550 & $24.8(22.1-27.7)$ & 8 & $1.0(0.4-2.5)$ & \\
\hline One & 840 & $36.5(33.4-39.7)$ & 792 & $24.8(22.1-27.7)$ & 30 & $27.2(25.5-29.1)$ & \\
\hline Two or more & 595 & $24.5(22.1-27.0)$ & 1,846 & $60.6(55.9-65.0)$ & 532 & $95.1(92.1-97.0)$ & \\
\hline Main chronic diseases & & & & & & & $<0.001$ \\
\hline Hypertension & 642 & $28.1(25.1-31.4)$ & 1,787 & $56.6(51.6-61.4)$ & 510 & $84.3(79.9-87.9)$ & \\
\hline Dyslipidemia & 367 & $14.4(12.5-16.6)$ & 1,036 & $31.6(28.5-34.9)$ & 338 & $57.8(51.8-63.6)$ & \\
\hline Arthritis, arthrosis, or rheumatism & 293 & $12.4(10.4-14.6)$ & 896 & $26.5(23.2-30.1)$ & 306 & $51.3(44.8-57.7)$ & \\
\hline Depression & 281 & $12.2(10.5-14.2)$ & 784 & $24.5(21.5-27.9)$ & 277 & $47.3(40.9-53.9)$ & \\
\hline Diabetes mellitus & 154 & $5.4(4.5-6.5)$ & 653 & $21.1(17.6-25.0)$ & 270 & $41.6(36.6-46.8)$ & \\
\hline Heart diseases & 99 & $3.4(2.4-4.7)$ & 300 & $9.9(8.1-12.1)$ & 198 & $33.3(27.0-40.3)$ & \\
\hline Chronic pulmonary disease & 210 & $8.4(6.9-10.1)$ & 401 & $10.7(9.0-12.6)$ & 121 & $18.5(14.4-23.5)$ & \\
\hline Stroke & 29 & $1.4(0.8-2.2)$ & 111 & $3.3(2.4-4.4)$ & 60 & $8.7(6.2-12.1)$ & \\
\hline Other diseases & 396 & $15.1(12.5-18.2)$ & 760 & $23.7(19.7-28.3)$ & 223 & $38.7(31.8-46.2)$ & \\
\hline Emergency care (yes) ${ }^{d}$ & 550 & $19.3(16.8-22.1)$ & 1,004 & $26.1(22.9-29.6)$ & 236 & $39.4(34.0-45.2)$ & $<0.001$ \\
\hline Hospitalization (yes) ${ }^{d}$ & 203 & $7.9(6.5-9.5)$ & 383 & $10.8(8.8-13.2)$ & 113 & $19.9(15.4-25.3)$ & $<0.001$ \\
\hline
\end{tabular}

a non-weighted n-value.

${ }^{b}$ Alcohol use considered positive for report of more than once per month.

c Report of practice of physical activity or sport in the three months preceding the interview.

d Self-report referring to the 12 months prior to the interview.

Source: PNAUM - Services, 2015. 
polypharmacy than those without it. Polypharmacy was significantly associated with age, being higher in older adults over 65 years old (OR 1.95 for people aged between 45 and 64 years old and OR 2.43 for the age group of 65 years old or more). There was association between polypharmacy and self-perception of health, and this association was inversely proportional to the worsening of self-perception (neither bad nor good OR 1.82; 95\%CI 1.40-2.38; bad/very bad OR 2.91; 95\%CI 1.93-4.38), to the report of having emergency health care (OR 1.59; 95\%CI 1.19-2.11) and to having chronic diseases, with the highest association in hypertensive patients (OR 3.49; 95\% CI 2.43-5.21). The association between the Country regions and polypharmacy was variable, and living in the South region showed higher association (5.8 times higher than in the North).

Table 3. Most used medicines by polypharmacy patients ${ }^{\mathrm{a}}$ of primary health care services, according the Anatomical Therapeutic Chemical Classification Index. National Survey on Access, Use and Promotion of Rational Use of Medicines - Services, 2015.

\begin{tabular}{|c|c|c|c|}
\hline Medicines & ATC Code $\left(5^{\text {th }} \text { level }\right)^{b}$ & $\mathbf{n}^{\mathrm{c}}$ & $\%(95 \% \mathrm{Cl})$ \\
\hline Simvastatin & C10AA01 & 224 & 35.7 (29.9-42.0) \\
\hline Losartan & C09CA01 & 213 & $34.0(26.9-41.8)$ \\
\hline Omeprazole & A02BC01 & 200 & $33.6(28.3-39.4)$ \\
\hline Acetylsalicylic acid & N02BA01 & 175 & $26.5(20.3-33.7)$ \\
\hline Metformin & A10BA02 & 161 & $24.8(18.1-33.0)$ \\
\hline Hydrochlorothiazide & C03AA03 & 159 & $23.5(16.8-31.9)$ \\
\hline Enalapril & C09AA02 & 101 & $15.8(10.9-22.3)$ \\
\hline Atenolol & C07AB03 & 101 & $15.0(10.3-21.5)$ \\
\hline Captopril+diuretic & C09BA01 & 65 & $12.2(7.0-20.5)$ \\
\hline Fluoxetine $^{\mathrm{d}}$ & N06AB03 & 64 & $12.2(9.3-15.9)$ \\
\hline Glibenclamide & A10BB01 & 67 & $11.4(7.7-16.5)$ \\
\hline Captopril & C09AA01 & 61 & $11.3(8.0-15.7)$ \\
\hline Clonazepam $^{\mathrm{d}}$ & N03AE01 & 60 & $11.2(8.9-13.9)$ \\
\hline Dipyrone & N02BB02 & 50 & $10.0(6.5-15.2)$ \\
\hline Ibuprofen $^{\mathrm{d}}$ & C01EB16 & 52 & $9.7(7.1-13.2)$ \\
\hline Propranolol & C07AA05 & 52 & $8.8(6.2-12.5)$ \\
\hline Paracetamol & N02BE01 & 58 & $8.7(6.6-11.3)$ \\
\hline Furosemide & C03CA01 & 55 & $8.7(6.8-11.0)$ \\
\hline Amlodipine & C08CA01 & 64 & $8.5(5.6-12.8)$ \\
\hline Losartan+diuretic & C09DA01 & 41 & $8.3(4.0-16.3)$ \\
\hline Diazepam $^{\mathrm{d}}$ & N05BA01 & 40 & $7.4(3.9-13.6)$ \\
\hline Diclofenac & M01AB05 & 30 & $6.8(4.6-10.1)$ \\
\hline Amitriptyline $^{d}$ & N06AA09 & 48 & $6.6(4.5-9.7)$ \\
\hline Metformin+sulfonylurea & A10BD02 & 24 & $6.0(2.0-17.1)$ \\
\hline Atenolol+thiazides & C07BB03 & 33 & $5.3(2.4-11.5)$ \\
\hline
\end{tabular}

${ }^{a}$ Use of five medicines or more.

${ }^{\mathrm{b}}$ Classification according to the WHO Collaborating Centre for Drug Statistics Methodology - Anatomical Therapeutic Chemical (ATC) Classification Index 2016.

${ }^{\mathrm{c}}$ non-weighted n-value.

d Potentially inappropriate medicines for use in people over 65 years old, according to Beers criteria. In Fick et al., 2003.

Source: PNAUM - Services, 2015. 
Table 4. Associated factors (odds ratio) with polypharmacy among patients of SUS primary health care services. National Survey on Access, Use and Promotion of Rational Use of Medicines - Services, 2015.

\begin{tabular}{|c|c|c|c|c|c|c|}
\hline \multirow{2}{*}{ Variable } & \multicolumn{2}{|c|}{ Univariate } & \multirow{2}{*}{$\mathbf{p}$} & \multicolumn{2}{|c|}{ Multiple $^{\mathbf{a}}$} & \multirow{2}{*}{ p } \\
\hline & OR & $95 \% \mathrm{Cl}$ & & OR & $95 \% \mathrm{Cl}$ & \\
\hline Intercept & - & - & - & 0.004 & $0.002-0.008$ & $<0.001$ \\
\hline \multicolumn{7}{|l|}{ Sex } \\
\hline Male & - & - & - & & & \\
\hline Female & 1.266 & $0.954-1.680$ & 0.103 & & & \\
\hline \multicolumn{7}{|l|}{ Age (years) } \\
\hline $18-44$ & - & - & - & - & - & - \\
\hline $45-64$ & 5.279 & $3.499-7.964$ & $<0.001$ & 1.946 & $1.275-2.970$ & $<0.001$ \\
\hline$\geq 65$ & 7.316 & $4.904-10.914$ & $<0.001$ & 2.428 & $1.541-3.825$ & $<0.001$ \\
\hline
\end{tabular}

Education level

Higher education

High school

1.131

$0.603-2.121$

0.702

Elementary or middle school

2.069

$1.051-4.071$

0.036

Some elementary or middle school

3.176

$1.768-5.706$

$<0.001$

Illiterate

4.296

$2.177-8.474$

$<0.001$

\section{Marital status}

\section{Single}

Married/common-law marriage

2.202

$1.572-3.084$

$<0.001$

Others

4.119

2.804-6.049

$<0.001$

Economic class

$$
\begin{aligned}
& \text { A or B } \\
& \text { C } \\
& \text { D or E }
\end{aligned}
$$$$
1.072
$$

1.143

$0.764-1.504$

0.686

$0.717-1.823$

0.574

Has health insurance

$$
\text { No }
$$

Yes

Hypertension

$$
\begin{aligned}
& \text { No } \\
& \text { Yes }
\end{aligned}
$$

Diabetes mellitus

$$
\begin{aligned}
& \text { No } \\
& \text { Yes }
\end{aligned}
$$

Depression

$$
\text { No }
$$

Yes

Arthritis

No

Yes

Self-perception of health

\section{Good/Very good}

Neither good nor bad

$\mathrm{Bad} /$ Very bad

Country region

$$
\text { North }
$$

\section{Midwest}

Northeast

Southeast

South

Emergency care

\section{No}

Yes

Hospitalization

$$
\text { No }
$$$$
\text { Yes }
$$

2.346

2.820
3.542
3.648
8.829

$1.814-6.913$

1.894-7.024

4.867-16.015

2.144

$1.688-2.722$

$<0.001$

0.005

$<0.001$

$<0.001$

$<0.001$

1.718-3.204

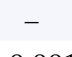

$-$

\section{$-$}

$<0.001$

$<0.001$
1.359-5.851

1.602

$1.125-2.278$

0.009

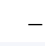

3.496

2.345-5.211

$<0.001$

-
2.297

1.753-3.009

$<0.001$

1.736

1.314-2.295

$<0.001$

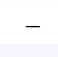

1.823

2.912

1.400-2.375

$<0.001$

$1.935-4.380$

$<0.001$

${ }^{a}$ Hosmer-Lemeshow test $=0.4228$.

Source: PNAUM - Services, 2015. 


\section{DISCUSSION}

The prevalence of polypharmacy observed in this study (9.4\%, 95\%CI 7.8-12.0) was similar to that of primary health care in Germany $(10.0 \%)^{12}$ and lower than the $20.8 \%$ in adults attended by primary health care in Scotland ${ }^{13}$. Polypharmacy in people over 65 years old (18.1\%) was higher than the $11.0 \%$ in older adults from areas covered by the Estratégia Saúde da Família (ESF - Family Health Strategy) in Recife, state of Pernambuco ${ }^{21}$, but lower than that found in other studies: $28.0 \%$ in the older adults in Goiânia ${ }^{27}, 32.7 \%$ among retirees in Rio de Janeiro ${ }^{24}$, $36 \%$ in the older adults in the city of São Paulo ${ }^{8}$, and $35.8 \%$ in North-American older adults ${ }^{22}$.

Studies on polypharmacy in primary health care, including the general population, are scarce ${ }^{12,13,19}$. Considering the process of population aging and evidence about the relationship between increasing age and number of prescription drugs, professionals must ensure the quality of pharmacotherapy in the health care process, avoiding the excessive use of multiple medicines ${ }^{7,13,15}$. Polypharmacy has been linked to negative health outcomes; increased morbidity and mortality; reduction of the quality of life, especially in older adults; and increased costs of care, with impact to patients and health care systems? ${ }^{7}$.

In recent years, geriatric polypharmacy has significantly increased. This group typically has a high comorbidity index, high risk for prescription of potentially inappropriate medicines, and are more susceptible to loss of doses or administration errors, which may impair adherence to treatment ${ }^{7,20}$. In addition, they often present a compromised nutritional status and pharmacokinetic and pharmacodynamic changes inherent to the aging process. These characteristics explain the greater vulnerability of older adults to the occurrence of adverse events, reduction of therapeutic efficacy, and increased risk of drug interactions s,20,21,27. $^{8}$. Observational studies have shown a strong relationship between the use of potentially inappropriate medications and adverse health outcomes, such as ADE (gastrointestinal bleeding, sedation, delirium, falls and fractures), hospitalization, and death ${ }^{2}$.

Although most studies investigated polypharmacy in older adults, this study showed a significant association between the age group of 45 to 64 years old and the use of five or more drugs. These data need to be better understood to guide public policies and qualify the assistance in primary health care. The model "one disease - one drug therapy" is an inadequate approach in face of the epidemic of medicine use in the $21^{\text {st }}$ century. As pointed out by Bjerrum et al. ${ }^{4}$, the implementation of information strategies for general practitioners on prescribing in primary care can improve this practice and reduce polypharmacy, qualifying health care.

The variables gender, economic class, marital status, and education level were less relevant in determining the consumption of multiple medicines in SUS primary health care. Loyola Filho, Uchoa, and Lima-Costa ${ }^{14}$ highlighted that only isolated studies have identified a relationship between higher education level, widowhood, and polypharmacy. Regarding sex, most national and international surveys $\mathrm{s}^{4,8,9,14,27}$ indicate that women seek more health services and that conditions inherent to their reproductive role, such as pregnancy and contraception, may explain the increased use of medicines ${ }^{14,15}$. However, this study did not observe association between gender and polypharmacy. Consistent with this result is the study of O'Dwyer et al. ${ }^{22}$ in a population over 40 years old in Ireland, which also found no association between polypharmacy and female sex.

Similar to other national studies ${ }^{8,21}$, individuals with health insurance presented a higher chance of polypharmacy. They have greater access to appointments with medical specialists, expanding the variety of prescriptions ${ }^{2.8}$. According to Neves et al. ${ }^{21}$, general practitioners of the Family Health Strategy normally prescribe items from SUS essential list, to enable the free drug supply. This practice reduces the amplitude of the therapeutic arsenal and, consequently, the average number of medicines prescribed per patient.

The self-assessment of health as regular and bad/very bad, observed by other studies, ${ }^{8,14,15,21}$, showed positive association with polypharmacy. According to Carvalho et al. ${ }^{8}$, these findings are consistent because the connection between health problems and medicine use is obvious. 
These results are reinforced by the association also verified with the emergency medical service, which may be related to a worse health condition. Furthermore, Mira et al. ${ }^{19}$ identified that $5 \%$ of medication errors in polypharmacy patients had serious consequences, requiring emergency care or hospitalization.

The association between self-report of hypertension, diabetes mellitus, depression, rheumatic diseases, and polypharmacy is in line with other national and international studies ${ }^{4,8,15,24}$. These are prevalent conditions in the Country, especially in older adults, whose control and treatment require the use of medicines. There is consistency between the 25 most used medicines by polypharmacy individuals and self-reported diseases. Hypertension, corroborating other studies ${ }^{8,21}$, was the most frequent chronic disease and presented the most intense association with polypharmacy.

The higher prevalence of medicines for the cardiovascular system (ATC group C) in the polypharmacy population corroborates with Charlesworth et al. ${ }^{9}$, who observed a relationship between the classes of antihypertensives, statins, and antidiabetics and the increase in the prevalence of drug use in American older adults. Qato et al. ${ }^{23}$ observed a statistically significant increase in the prescription of statins in the United States of America, reaching $46.2 \%$ of people over 65 years old, in 2011. Evidence on the clinical use of statins are controversial, with some studies showing its usefulness in reducing morbidity and mortality and others showing its potential damage ${ }^{11}$.

The high use of omeprazole in this study may be explained, according to Carvalho et al. , by the prophylactic and not always rational prescription of drugs for reducing gastric acidity. Often, an adverse reaction can be interpreted as new clinical entity, being treated with new medication, which constitutes an iatrogenic cascade ${ }^{8}$. Bjerrum et al. ${ }^{4}$ point out that some authors consider polypharmacy an "uncontrolled experiment," because most individuals has a unique combination of medicines and, therefore, require individualized care and therapeutic conciliation.

Among the most used medicines by the polypharmacy patients, we highlight five items (amitriptyline, clonazepam, diazepam, fluoxetine, and ibuprofen), which belong to the list of potentially inappropriate medications for use in older adults, according to Beers criteria ${ }^{3}$. These results are very relevant when considering that the age group above 65 years old was associated with the greatest chance of polypharmacy within the primary health care of SUS. The Beers criteria is an important measure of quality of health care in older adults, and it should be incorporated into electronic record systems to support the prescription process and to identify situations in which non-pharmacological alternatives would be more appropriated ${ }^{2,3}$.

The polypharmacy varied according to Brazilian regions, with greater association in the South and Southeast. These results can be explained by the characteristics of the population sampled, because individuals of these regions showed higher prevalence of comorbidities. In addition, the states of those regions have a higher health care insurance coverage, variable predictive of polypharmacy in this study ${ }^{18}$.

As Rozenfeld et al..$^{24}$ point out, polypharmacy is not always a preventable event. Chronic diseases of high prevalence, such as hypertension and diabetes mellitus, are typically handled by association of medicines. The review of drugs and the potential deprescription should be evaluated mainly by physicians or pharmacists, to customize the treatment in people with multimorbidity or specific vulnerability. Also, the monitoring for the potential occurrence of drug interactions is important ${ }^{13}$. According to Secoli et al..$^{26}$, the evaluation of multiple therapeutic regimens, especially in older adults, allows the identification of associations with potential drug interactions and their suspension, to minimize the damage and qualify the medicine use. Protocols and guidelines for the management of the most prevalent chronic diseases must contain, in addition to the treatment indications, recommendations about situations where deprescription can be adopted. 
There is evidence that prescribers' education, with emphasis on stimulating preventive practices, impacts adherence to therapy and the quality of medicines use ${ }^{25}$. Mira et al. ${ }^{19}$ found that only $32.5 \%$ of patients attended by the Spanish primary health care were asked by physicians about drugs prescribed by other health professionals. In this study, the medication errors were associated with: feeling of not being listened to, loss of confidence in the physician, occurrence of simultaneous prescriptions by several medical specialists, and incongruent information between different health professionals.

Pharmaceutical care services, with appointments to develop care plans, to solve problems related to medicines, and to provide timely follow-up, focusing on the acquisition of skills for the co-responsibility, can improve adherence to drug therapy and, consequently, clinical outcomes. The adoption of strategies for the self-registration of all medicines used by patients, including medicinal plants, non-prescription drugs, and dietary supplements, may contribute to the clinical history improvement, reducing the memory bias 6 .

This study has some limitations. Because it is the first nationwide study on polypharmacy in patients of public health services, there are methodological differences and diversity between the populations of the studies used to data discussion, which restricts the direct comparison. Another limitation refers to the polypharmacy concept adopted, considered only as the concomitant use of multiple medicines. We did not verify the reasons for drug prescription, to assess the appropriateness of the use of each medicine. In addition, the data presented may be underestimated by memory constraints, because medicines and diseases were self-reported by patients. Because it is a cross-sectional study, it is not possible to establish the temporality of the associated factors.

Despite the presented limitations, the results showed a high rate of polypharmacy, especially in the elderly population, which needs to be better understood by managers and multidisciplinary health teams. Reducing avoidable complications and medication errors are increasing needs and should promote the adoption of safe practices, based on scientific evidence. According to Bjerrum et al. ${ }^{4}$, programs designed to reduce problems associated with polypharmacy are more effective when developed for subgroups of patients with increased risk. In the health care process, the establishment of co-responsibility and solidarity links with patients and their families contribute to the strengthening of the patient's safety ${ }^{17}$.

In conclusion, polypharmacy is a reality in the population attended by the SUS primary health care. The recent epidemiological changes, with the increase in life expectancy and, consequently, chronic diseases, has changed the perspective on the use of multiple medicines in health care. Considering the important role of the drug public supply in Brazil, this study provides subsidies for the improvement of prescribing practices and use of medicines. Activities to increase drug safety in sub-populations with a greater chance of polypharmacy have the potential to reduce preventable adverse events, especially in older adults.

The number of drugs prescribed should consider the real needs of each patient and the balance between potential benefits and risks. The main challenge to qualify health care is to ensure that the prescription of multiple drugs is appropriate and safe. Regular evaluation of the therapeutic regimens, focusing on adherence, adjustment to individual preferences, and risk identification can minimize the damage and maximize the benefits. Continued professional training, multidisciplinary team work, and population education are important strategies to qualify the use of medicines and strengthen the Política Nacional de Segurança do Paciente (PNSP - National Policy for Patient Safety).

\section{REFERENCES}

1. Álvares J, Alves MCGP, Escuder MML, Almeida AM, Izidoro JB, Guerra Junior AA, et al. Pesquisa Nacional sobre Acesso, Utilização e Promoção do Uso Racional de Medicamentos: métodos. Rev Saude Publica. 2017;51 Supl 2:4s. https://doi.org/10.11606/S1518-8787.2017051007027 
2. American Geriatrics Society. Updated Beers Criteria for Potentially Inappropriate Medication Use in Older Adults: The American Geriatrics Society 2012 Beers Criteria Update Expert Panel. J Am Geriatr Soc. 2012;60(4):616-31. https://doi.org/10.1111/j.1532-5415.2012.03923.x

3. American Geriatrics Society. 2015 Updated Beers Criteria for Potentially Inappropriate Medication Use in Older Adults. J Am Geriatr Soc. 2015;63(11):2227-46. https://doi.org/10.1111/jgs.13702

4. Bjerrum L, Sogaard J, Hallas J, Kragstrup J. Polypharmacy: correlations with sex, age and drug regimen: a prescription database study. Eur J Clin Pharmacol. 1998;54(3):197-202. https://doi.org/10.1007/s002280050445

5. Bourgeois FT, Shannon MW, Valim C, Mandl KD. Adverse drug events in the outpatient setting: an 11-year national analysis. Pharmacoepidemiol Drug Saf. 2010;19(9):901-10. https://doi.org/10.1002/pds.1984

6. Bushardt RL, Massey EB, Simpson TW, Ariail JC, Simpson KN. Polypharmacy: misleading, but manageable. Clin Interv Aging. 2008;3(2):383-9. https://doi.org/10.2147/CIA.S2468

7. Cadogan CA, Ryan C, Hughes CM. Appropriate polypharmacy and medicine safety: when many is not too many. Drug Saf. 2016;39(2):109-16. https://doi.org/10.1007/s40264-015-0378-5

8. Carvalho MFC, Romano-Lieber NS, Bergsten-Mendes G, Secoli SR, Ribeiro E, Lebrão ML, et al. Polifarmácia entre idosos do Município de São Paulo - Estudo SABE. Rev Bras Epidemiol. 2012;15(4):817-27. https://doi.org/10.1590/S1415-790X2012000400013

9. Charlesworth CJ, Smit E, Lee DSH, Alramadhan F, Odden MC. Polypharmacy among adults aged 65 years and older in the United States: 1988-2010. J Gerontol A Biol Med Sci. 2015;70(8):989-95. https://doi.org/10.1093/gerona/glv013

10. Donabedian A. An introduction to quality assurance in health care. New York: Oxford University Press; 2003.

11. Finegold JA, Shun-Shin MJ, Cole GD, Zaman S, Maznyczka A, Zaman S, et al. Distribution of lifespan gain from primary prevention intervention. Open Heart. 2016;3(1):e000343. https://doi.org/10.1136/openhrt-2015-000343

12. Grimmsmann T, Himmel W. Polypharmacy in primary care practices: an analysis using a large health insurance database. Pharmacoepidemiol Drug Saf. 2009;18(12):1206-13. https://doi.org/10.1002/pds.1841

13. Guthrie B, Makubate B, Hernandez-Santiago V, Dreischulte T. The rising tide of polypharmacy and drug-drug interactions: population database analysis 1995-2010. BMC Med. 2015;13:74. https://doi.org/10.1186/s12916-015-0322-7

14. Loyola Filho Al, Uchoa E, Lima-Costa MF. Estudo epidemiológico de base populacional sobre uso de medicamentos entre idosos na Região Metropolitana de Belo Horizonte, Minas Gerais, Brasil. Cad Saude Publica. 2006;22(12):2657-67. https://doi.org/10.1590/S0102-311X2006001200015

15. Macovic-Pecovik V, Skrbic R, Petrovic A, Vlahovic-Palcevski V, Mrak J, Bennie M et al. Polypharmacy among the elderly in the Republic of Srpska: extent and implications for the future. Expert Rev Pharmacoecon Outcomes Res. 2016;16(5):609-18. https://doi.org/10.1586/14737167.2016.1115347

16. Medeiros-Souza P, Santos-Neto LL, Kusano LTE, Pereira MG. Diagnosis and control of polypharmacy in the elderly. Rev Saude Publica. 2007;41(6):1049-1053. https://doi.org/10.1590/ S0034-89102006005000050

17. Ministério da Saúde (BR). Portaria no 529, de 01 de abril de 2013. Institui o Programa Nacional de Segurança do Paciente (PNSP). Diario Oficial Uniao. 2 abril 2013 [cited 2016 Mar 10]; Seção I:43. http://bvsms.saude.gov.br/bvs/saudelegis/gm/2013/prt0529_01_04_2013.html

18. Ministério da Saúde (BR), Agência Nacional de Saúde Suplementar. Caderno de informação da Saúde Suplementar: beneficiários, operadoras e planos. Rio de Janeiro: ANS; 2014 [cited 2016 Mar 11]. Disponível em: http://www.ans.gov.br/images/stories/Materiais_para_pesquisa/Perfil_ setor/Cadernoinformacao_saude_suplementar/2014_mes06_caderno_informacao.pdf

19. Mira JJ, Orozco-Beltrán D, Pérez-Jover V, Martínez-Jimeno L, Gil-Guillén VF, Carratala-Munuera $\mathrm{C}$, et al. Physician patient communication failure facilitates medication errors in older polymedicated patients with multiple comorbidities. Fam Pract. 2013;30(1):56-63. https://doi.org/10.1093/fampra/cms046 
20. Mukete BN, Keith C, Ferdinand MD, FACC FAHA. Polypharmacy in older adults with hypertension: a comprehensive review. J Clin Hypertens (Greenwich). 2016;18(1):10-8. https://doi.org/10.1111/jch.12624

21. Neves SJF, Marques APO, Leal MCC, Diniz AS, Medeiros TS, Arruda IKG. Epidemiologia do uso de medicamentos entre idosos em área urbana do Nordeste do Brasil. Rev Saude Publica. 2013;47(4):759-68. https://doi.org/10.1590/S0034-8910.2013047003768

22. O'Dwyer M, Peklar J, McCallion P, McCarron M, Henman MC. Factors associated with polypharmacy and excessive polypharmacy in older people with intellectual disability differ from the general population: a cross-sectional observational nationwide study. BMJ Open. 2016;6(4):e010505. https://doi.org/10.1136/bmjopen-2015-010505

23. Qato DM, Wilder J, Schumm LP, Gillet V, Alexander GC. Changes in prescription and over-thecounter medication and dietary supplement use among older adults in the United States, 2005 vs 2011. JAMA Intern Med. 2016;176(4):473-82. https://doi.org/10.001/jamainternmed.2015.8581

24. Rozenfeld S, Fonseca MJM, Acurcio FA. Drug utilization and polypharmacy among the elderly: a survey in Rio de Janeiro City, Brazil. Rev Panam Salud Publica. 2008;23(1):34-43. https://doi.org/10.1590/S1020-49892008000100005

25. Ryan R, Santesso N, Lowe D, Hill S, Grimshaw J, Prictor M, et al. Interventions to improve safe and effective medicines use by consumers: an overview of systematic reviews. Cochrane Database Syst Rev. 2014;(4):CD007768. https://doi.org/ 10.1002/14651858.CD007768.pub3

26. Secoli SR, Danzi NJ, Lima FFF, Lorenzi Filho G, Cesar LAM. Interações medicamentosas em pacientes coronariopatas. Rev Bras Cardiol. 2012 [cited 2016 Mar 10]; 25(1):11-8. Available from: http://www.rbconline.org.br/wp-content/uploads/v25n1_1.pdf

27. Silveira EA, Dalastra L, Pagotto V. Polifarmácia, doenças crônicas e marcadores nutricionais em idosos. Rev Bras Epidemiol. 2014;17(4):818-29. https://doi.org/10.1590/1809-4503201400040002

28. World Health Organization (WHO), World Alliance for Patient safety, The Research Priority Setting Working Group. Summary of The Evidence on Patient Safety: implications for research. Geneva: WHO; 2008 [cited 2017 Feb 25]. Available from: http://apps.who.int/iris/ bitstream/10665/43874/1/9789241596541_eng.pdf

29. WHO Collaborating Centre for Drug Statistics Methodology. Anatomical Therapeutic Chemical (ATC) Classification Index 2016. Oslo; 2016 [cited 2016 Mar 10]. Available from: http://www. whocc.no/atc_ddd_index/

Funding: Department for Pharmaceutical Services and Strategic Health Supplies and Department of Science and Technology of the Secretariat of Science, Technology and Strategic Supplies of the Brazilian Ministry of Health (SCTIE/MS - Process 25000.111834/2, Decentralization of FNS Resources).

Authors' Contribution: All authors contributed substantially in the design and planning of the study. RCRMN contributed to data analysis and interpretation and to the writing of the final version of the manuscript. ICG contributed to data analysis and interpretation.JA, FAA, and AAG Jr. coordinated the research and contributed to the discussion of the structure of the article and to the writing of the final version of the manuscript. MRS, EAC, OMS, SNL, KSC, MGOK, and IAG contributed to the discussion of the structure of the article; to the critical review of the content; and to the approval of the final version of the manuscript. All authors declare to be responsible for all aspects of the study, ensuring its accuracy and completeness.

Conflict of Interest: KSC declares conflict of interest for being former director of the Brazilian Ministry of Health, the research funding institution. The other authors declare no conflict of interest. 